\title{
Impact of R\&D expenditures, rainfall and temperature variations in agricultural productivity: Empirical evidence from Bangladesh
}

\author{
Ruhul Salim $^{1 *}$, Kamrul Hassan ${ }^{2}$, Sanzidur Rahman ${ }^{3}$, \\ ${ }^{1}$ School of Economics \& Finance, Curtin Business School, \\ Curtin University, Perth, WA 6845, Australia \\ ${ }^{2}$ Department of Finance, School of Management and Governance \\ Murdoch University, 90 South St. Perth, WA 6150, Australia \\ ${ }^{3}$ Faculty of Economics, Shandong University of Finance and Economics, \\ Jinan, Shandong Province, Postcode - 250001, China.
}

* Corresponding author. School of Economics \& Finance, Curtin Business School (CBS), Curtin University, P.
O. Box U1987, Perth, WA 6845, Australia. e-mails: Ruhul.Salim@cbs.curtin.edu.au 


\title{
Impact of $R \& D$ expenditures, rainfall and temperature variations in agricultural productivity: Empirical evidence from Bangladesh
}

\begin{abstract}
This study aims to investigate dynamic relationships between research and development $(R \& D)$ expenditure, climate change (measured by annual rainfall and temperature variations), human capital (proxied by literacy) and total factor productivity (TFP) growth in Bangladesh agriculture. Pesaran's Pooled Mean Group (PMG) estimator is used to a unique panel data of 17 regions of Bangladesh covering a 61-year period (1948-2008). In addition, the panel vector autoregression (PVAR) model is also applied to trace the responsiveness of TFP from a shock to $R \& D$, extension services, and literacy rate. Results reveal that $R \& D$ has an insignificant impact on TFP in the short-run, while it has a significant positive impact in the long-run. The contributions of climate variables (i.e., rainfall and temperature variations) are highly significant and negative in the long run. The literacy rate is found to have a significant positive impact on TFP as expected. These results suggest that agricultural $R \& D$ investment and human capital could play an important role to ameliorate the adverse effects of climate change in the agricultural sector of Bangladesh.
\end{abstract}

Key Words: Climate change, R\&D investment, agricultural productivity growth, panel data, co-integration, Bangladesh

JEL Classification: Total factor productivity, R\&D expenditure, Panel data, Bangladesh

\section{Introduction}

Agriculture still plays a vital role in the economy of Bangladesh in this $21^{\text {st }}$ century contributing approximately 15 per cent to the national Gross Domestic Product (GDP) and employing over 43 per cent of the total labour force (Alam, 2018). Therefore, productivity improvement in agriculture is important for sustainable economic development in Bangladesh. Moreover, an increase in agricultural productivity releases resources that can be diverted to expand the nonagricultural sector of the economy (O’Donnell, 2010). Total factor productivity (TFP) captures the effect of technical change due to enhance spending in research and development (R\&D) as well as investment in agricultural infrastructure. Higher TFP is desirable, as it not just suggests a higher yield from the application of technology and better utilisation of resources, but also it leads to a decrease in poverty in rural areas, which remains a major development objective of 
the Bangladesh government.

Recently, Rahman and Salim (2013) have noted that R\&D investment and extension expenditure are significant determinants of agricultural TFP growth in Bangladesh. Similarly, other studies have also noted a positive influence of R\&D on TFP in developing countries (Pardey et al., 2006) and developed countries (Andersen and Song, 2013; Salim and Islam, 2010). These studies provide evidence that $R \& D$ is an important determinant of TFP growth in an economy. Thus, investments in agricultural $R \& D$ are central to the improvement in agricultural productivity growth. These R\&D investments generate stock of knowledge and diffuse modern technologies in an economy. The knowledge contributes to the effective use of existing resources and thereby raises productivity level. Consequently, R\&D reduces the use of input and save resource base (Pardey, et al., 2006). However, these effects are not spontaneous. Some recent studies in the United States of American (USA) agriculture have demonstrated that the effect of R\&D takes about 14 to 50 years to influence agricultural TFP growth. For instance, to take into account the effects of R\&D in TFP growth Rahman and Salim (2013) have used a lag length of 14-years, and Human and Evenson (2006) have used 35-years lag of the variable representing $R \& D$ investment in their studies.

Agriculture is vulnerable to climatic conditions such as rising temperature and/ rainfall variations. Concerns on the effects of changing climatic conditions on agriculture are well documented. However, the focus of these studies is on examining how the structure of agriculture, food production or agricultural land use will change in response to changing climatic conditions in the future (Salvati et al., 2013; Lobell et al., 2011; Benhin, 2008; Morton, 2007). The long-run relationship between climate change and agricultural TFP growth remains under-researched and is indeed non-existent in a developing country context. Salim and Islam (2010) examine the impact of R\&D and climate change on the Western Australian agricultural sector using standard time series econometrics covering a shorter time horizon of 28 years (1977-2005). These authors conclude that both R\&D expenditure and climate change influence long-run productivity growth in agriculture. One possible reason for sparse studies covering this important issue is that the measurement of agricultural productivity under variable climatic conditions is difficult because of the unavailability of long-term data and appropriate methodology (O'Donnell et al. 2006). It is imperative that growth in agriculture have to rely on the application and development of modern technologies, which in turn is dependent on investment in $R \& D$.

This study aims to contribute to this scant literature by examining the long-run 
relationship between climate change (proxied by variations in temperature and rainfall), $R \& D$ investment and productivity growth in agriculture for a developing economy, i.e., Bangladesh. The impressive productivity growth in Bangladesh agriculture for the past three decades (Deb, 2016) motivates us to examine the role of $R \& D$ and climate change in Bangladesh agriculture. Furthermore, Bangladesh being a dominant rice-producing country relies heavily on monsoon rainfall. Rice produced during the Aman season (the monsoon season) provides the bulk of the national production and is heavily dependent on rainfall while supplementary irrigation is the main source of water for the Boro season rice (in the dry winter season). Therefore, the ensuing focus has been on finding the determinants of productivity in agriculture in general while taking into consideration the variability in climatic conditions within which agriculture operates. We accomplish this task by employing a suite of recently developed dynamic time-series econometrics on a long-run panel data series of 17 regions (former districts) covering a long 61-year period (1948-2008) from Bangladesh, a country highly vulnerable to climate change.

This study contributes to the existing scant literature in several ways. First, this study attempts to simultaneously analyse the causal relationships of the three key variables (i.e., climate change, R\&D investment, and agricultural productivity), which overcomes several limitations identified in the existing literature. One such limitation of the previous studies examining the determinants of long-run productivity growth is that those studies ignored the roles of R\&D and climatic factor simultaneously in empirical studies (Mondol, 2010; Mullen, 2010; among others). As a result, climatic factors were subsumed in the error term thereby causing the problem of endogeneity because of the obvious missing variable problem. Second, this study applies the recently developed and improved methodology, which overcomes the problem of panel heterogeneity in the cross-sectional time-series studies. The traditional vector autoregressive model (VAR) model used in some previous studies ignores the unit-specific or time-specific effects both in short-run and long-run effects (Salim and Islam, 2010 and Thirtle, et al. 2008) of variables and thus, generate inconsistent estimates of the parameter coefficients in the model. Pesaran et al. (1999) have suggested the use of panel heterogeneous model and Pooled Mean Group (PMG) estimation technique in order to resolve the aforementioned problem. This study applies this technique in empirical estimation.

The rest of the paper is organised as follows. Section 2 presents an overview of $R \& D$ investment in Bangladesh agriculture. Section 3 presents the econometric methodologies. In Section 4, data sources and the model are discussed providing a brief outline of the analytical framework. Section 5 discusses the empirical results while Section 6 concludes and draws some policy implications. 


\section{An overview of $R \& D$ investment in Bangladesh agriculture}

Though agricultural research is considered widely an important source of productivity growth, insufficient investment in R\&D is a challenge of Bangladeshi agriculture (Mondol, 2010). The government of Bangladesh (GoB) predominantly invests in $R \& D$ in agriculture through a number of government institutions, such as Bangladesh Agricultural Research Institute (BARI), Bangladesh Rice Research Institute, Bangladesh Jute Research Institute, Sugarcane Research Institute, and Agricultural Extension Services and so on. BARI is the largest research institute accounting 29 per cent of the country's research capacity; and it alone has invested $70 \%$ of the total R\&D investment in 2009 (Rahija, et al. 2011). These organizations function under the administration of the Ministry of Agriculture (MoA). In addition, there are some private $R \& D$ investments. These investments are made by the donor agencies, such as Food and Agricultural Organisation (FAO), World Bank (WB) and Asian Development Bank (ADB) and public higher education agencies, including public universities. Thirty-two higher education agencies, including public universities, are working in agricultural R\&D.

Figure 1: R\&D and TFP changes, 1971-2008

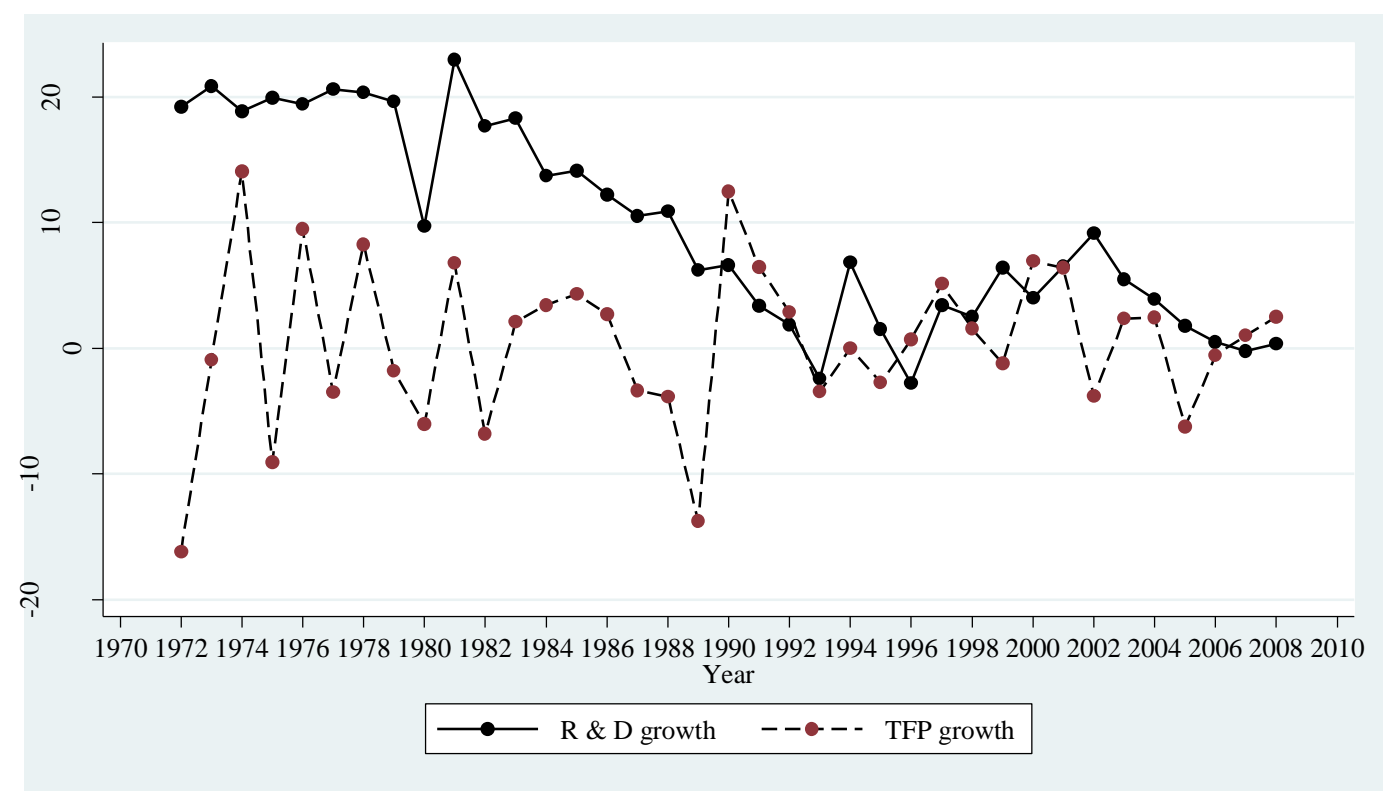

Source: Authors' calculation using data collected from BBS and Rahman and Salim (2013).

Figure 1 presents the growth in government R\&D (in percentage) and TFP growth for the period 1971-2007. The figure shows that there are large fluctuations in R\&D and TFP growth over time. This figure reveals that between 1972 and 1980 the growth of R\&D was very stable. Immediately after 1982 until the year 1993, the growth declined sharply. As Bangladesh gained its independence in 1971 from erstwhile Pakistan, the government of Bangladesh (GoB) 
has embarked on investing other priority sectors rather than agricultural $R \& D$ to cope with the post-independence economic crisis. In 1997 investment in agricultural R\&D was only $0.20 \%$ of gross domestic product (GDP) (Karim, 1997). The agricultural TFP growth also has passed through a cycle of ups and downs throughout the 1972-2008 period. The cyclical process is due to the adaptation of green revolution and the agricultural reform in the agricultural sector during the 1990s (Rahman and Salim 2013). Further, during this period, technological progress powered agricultural TFP growth at the rate of 0.74 per cent per annum and the other sources of productivity growth have been $\mathrm{R} \& \mathrm{D}$ investment, farm size, crop specialisation, and agricultural extension expenditure.

The International Food Policy Research Institute (IFPRI) recommends intensity ratio (total public agricultural R\&D spending as a percentage of agricultural gross domestic product -AgGDP), an internationally comparable measure to get an overview of R\&D spending in an economy. According to this measure, Bangladesh invested around $0.5 \%$ for R\&D spending in 1991 and 2002, and the figure was half of the suggested level of investment (Beintena and Stads, 2003). After 1992, the level of investment started to increase and reached its peak in 2004, however, it still remains lower than 1\% of AgGDP. Rice productivity has been the most dominant research area in Bangladesh. In 2009, 50\% of the researchers focused on productivity in rice, $13 \%$ on livestock, 7 per cent on post-harvest issues and 6\% on fisheries (Rahija, et al. 2011).

\section{Data description and the empirical model}

\subsection{Description of data}

Various sources are used to construct the database needed for this study. Data on the Bangladesh agricultural sector are taken from the special issue of the Statistical Yearbook of Bangladesh covering the period 1948-1972 (BBS, 1975), andvarious issues of the annual Statistical Yearbook of Bangladesh covering the period 1975 to 2008 (BBS, various issues). Other data types used in the study (agricultural TFP index, R\&D investment, human capital, and climate change) are sourced from a recent study conducted by Rahman and Salim (2013).

$\mathrm{R} \& \mathrm{D}$ is one of the main variables of interest in this study. The data on investment in R\&D include only publicly funded (Government) research expenditure. We could not include private $R \& D$ funding in our calculation covering such a long time period because such data is simply not recorded or available in any shape or form. The variable is measured as real government budget expenditure for R\&D activities by the government agencies. The unit of measurement is Bangladeshi currency, taka (BDT). The variable is measured at constant prices 
taking 1984-85 as a base price. The R\&D data are converted to a data series by taking into account 14-year long time lag required for the stock of knowledge generated by the research to be translated into useful technology to the farmers for adaptation following Dey and Evenson (1991). The lag is accounted for by the weighted sum of research expenditures for 14 years. This variable is constructed by summing up the values generated by multiplying research investment in a given year $\left(R_{t-i}\right)$ by a given weight $\left(w_{t-i}\right)$. That is the construction of this variable is done by $\sum\left(w_{t-i} \times R_{t-i}\right)$. The weight for current year research is taken zero. For 1year lag, the weight is 0.2 , for 2-year lag the weight is 0.4 and so on. Since R\&D expenditure data is available at the national level, we convert them on a per-district basis using the following formula: $f_{i, t}^{R \& D}=\frac{R \& D_{t}}{\sum_{i=1}^{17} f_{i, t}^{n}} \times f_{i, t}^{n}$, where $f_{i, t}^{R \& D}=\mathrm{R} \& \mathrm{D}$ expenditure of district $i$ in year $t$; $\sum_{i=1}^{17} f_{i, t}^{n}=$ Sum of firms in all 17 districts in year $\mathrm{t} ; \mathrm{R} \& \mathrm{D}_{\mathrm{t}}=$ Total $\mathrm{R} \& \mathrm{D}$ expenditure in year $t$; and $f_{i, t}^{n}=$ Number of firms in district $i$ in year $\mathrm{t}$. The number of farms is taken from the census documents, i.e., Census of Pakistan 1951 and agricultural censuses of 1960, 1983-84, 1996 and 2008. Standard linear trend extrapolation model is used to complete the series of the intercensus years. Log of R\&D expenditure per district (lrnd) is used in subsequent analyses.

The Ministry of Agriculture of the Government of Bangladesh incurs all expenditure for agricultural extension services. The variable is measured by Bangladeshi Taka (BDT) at constant price taking 1984-85 as the base year. The data for the period of 1942-1970 is collected from the Pakistan Planning Commission Reports. The unit of the variable is Million BDT. This variable is also converted into a per-district basis using the formula mentioned above in describing $\mathrm{R} \& \mathrm{D}$ variable. Log of this variable (lext) is used in our subsequent analyses. The other two control variables are human capital and climatic conditions. Human capital is measured by the average literacy rate (henceforth 'literacy' only) at the district level. The average literacy rate is calculated for the population aged 7 years and above. Finally, climate change is measured by total annual rainfall in millimetres and temperature in Celsius degrees. We use 30 years moving average of rainfall; however, we do not lose any data point in doing so, since rainfall data are from 1903. The data is sourced from the Bangladesh Meteorology Department. Log of this variable (lrain30yma) is used in our analysis.

For temperature, we construct two variables: growing degrees month (GDM) and 30 years moving average. GDM is crops' accumulated exposure to optimal growing temperature. Deschenes and Greenstone (2007) note that for optimal growth temperature must be between a lower and an upper bound. Although heat absorption capacity varies across crops, existing 
literature $^{1}$ following Ritchie and NeSmith (1991) who suggest a minimum of $8^{\circ} \mathrm{C}$ and maximum of $32^{\circ} \mathrm{C}$ for the entire agricultural sector. In the literature, it is usually constructed using daily temperature and called growing degrees days (GDD); however, in the present case we do not have daily temperature data, instead, we have monthly data only. Accordingly, we construct growing degrees month $(\mathrm{GDM})$ variable by taking the sum of $\min \left\{\frac{T_{H}+T_{L}}{2}, T_{U B}\right\}-$ $T_{L B}$ for each month, where $T_{\mathrm{H}}$ and $T_{\mathrm{L}}$ are the highest and lowest temperature of the month respectively, $T_{\mathrm{UB}}$ and $T_{\mathrm{LB}}$ are the upper and lower bounds growing temperature respectively in constructing GDM, we follow Ritchie and NeSmith (1991) and take the values of $T_{\mathrm{UB}}$ and $T_{\mathrm{LB}}$ as $32^{\circ} \mathrm{C}$ and $8^{\circ} \mathrm{C}$ respectively. We use a $\log$ of this variable $(\lg d m)$ for our analyses. A second temperature proxy used in the analysis is 30 years moving average of national-level mean temperature, which is available from 1901; therefore, in constructing 30 years moving average data we do not lose any data point for our sample period. This variable is also used in its logarithmic form (ltmp30yma).

Table 1 presents the descriptive statistics of all these data series. Variations, as indicated by the coefficient of variation $(\mathrm{CV})$, show that the climate variables (lgdm, lrain30yma and ltmp30yma) have the lowest variations. This is expected since climate change takes place very slowly. Among other variables, literacy has the highest variation followed by extension service (lext, tfp and $l r n d$ ). Skewness and kurtosis values indicate that all series have an asymmetric

\footnotetext{
${ }^{1}$ See for example, Roberts et al., (2012)
} 
Table 1: Descriptive statistics

\begin{tabular}{|c|c|c|c|c|c|c|c|}
\hline & lexperfirm & $\operatorname{lgdm}$ & literacy & lrain30yma & ltmp30yma & lrndperfirm & $\mathrm{tfp}$ \\
\hline Mean & 3.759 & 2.326 & 29.754 & 3.322 & 1.406 & 6.569 & 0.469 \\
\hline Std. Dev. & 1.087 & 0.013 & 12.155 & 0.109 & 0.005 & 1.157 & 0.100 \\
\hline Coefficient of variation & 28.910 & 0.551 & 40.851 & 3.311 & 0.358 & 17.613 & 21.305 \\
\hline Skewness & 0.243 & -0.055 & 0.859 & 0.627 & 0.628 & -1.114 & -0.516 \\
\hline Kurtosis & 1.811 & 2.814 & 2.958 & 2.719 & 2.970 & 4.241 & 3.805 \\
\hline Jarque-Bera & 71.254 & 2.031 & 127.817 & 71.485 & 68.354 & 281.163 & 74.119 \\
\hline$(p$-value $)$ & 0.000 & 0.362 & 0.000 & 0.000 & 0.000 & 0.000 & 0.000 \\
\hline \multicolumn{8}{|l|}{ Panel unit root test } \\
\hline Pesaran $(2007)^{\mathrm{a}}$ & $\begin{array}{c}0.060 \\
(4.835)\end{array}$ & $\begin{array}{l}-10.020 * * * \\
(-9.690 * * *)\end{array}$ & $\begin{array}{c}-1.717 * * \\
(1.088)\end{array}$ & $\begin{array}{c}1.592 \\
(-1.098)\end{array}$ & $\begin{array}{c}1.444 \\
(-4.308 * * *)\end{array}$ & $\begin{array}{l}-1.868 \\
(0.355)\end{array}$ & $\begin{array}{c}-5.114 * * * \\
(-6.678 * * *)\end{array}$ \\
\hline Herwartz and Siedenburg (2008) & $\begin{array}{c}1.365 \\
\left(-1.397^{*}\right)\end{array}$ & $\begin{array}{c}-5.308 * * * \\
(-4.528 * * *)\end{array}$ & $\begin{array}{c}0.130 \\
(-0.110)\end{array}$ & $\begin{array}{c}0.479 \\
(1.537)\end{array}$ & $\begin{array}{c}1.418 \\
(1.080)\end{array}$ & $\begin{array}{c}5.321 \\
(2.776)\end{array}$ & $\begin{array}{l}-2.787 * * * \\
(-1.881 * *)\end{array}$ \\
\hline Demetrescu and Hanck (2012) & $\begin{array}{c}1.921 \\
(-1.084)\end{array}$ & $\begin{array}{c}-4.563 * * * \\
(-3.773 * * *)\end{array}$ & $\begin{array}{c}0.955 \\
(0.047)\end{array}$ & $\begin{array}{l}-0.035 \\
(2.348)\end{array}$ & $\begin{array}{c}2.336 \\
(0.354)\end{array}$ & $\begin{array}{c}5.557 \\
(0.675)\end{array}$ & $\begin{array}{l}-2.198 * * \\
(-1.74888)\end{array}$ \\
\hline Herwartz et al. (2017) & -0.920 & $-4.447 * * *$ & 0.083 & 2.151 & 2.171 & 8.594 & $-2.525 * * *$ \\
\hline
\end{tabular}

Note: (1) First figures in Pesaran (2007), Herwartz and Siedenburg (2008) and Demetrescu and Hanck (2012) panel unit root test results are test statistics without trend in test equation and those in the parentheses correspond to test equation with trend, while Herwartz et al. (2017) includes trend by default. (2) *, ** and $* * *$ indicate significant at $10 \%, 5 \%$ and $1 \%$ level respectively. (3) Variables for which panel unit root test statistics are not significant are found to be first difference stationary; however, results not reported, available upon request.

a 5 lags are used in Pesaran (2007) unit root test to take care of serial correlation in data 
distribution with fat tails, except $l g d m$, which is normally distributed as indicated by insignificant Jarque-Bera test statistic. The bottom part of the table reports mean reversion property of the variables under study. We employ widely used panel unit root of Pesaran (2007) which is robust to cross-sectional dependence and three recently available third-generation panel unit root tests of Herwartz and Siedenburg (2008) and Demetrescu and Hanck (2012) which are robust to cross-sectional dependence and non-stationary volatility in a panel. We also use Herwartz et al. (2017) test, which is robust to trending heteroskedastic data. Before applying this test, we visualize the series to make sure that the data contains a trend. Unit test results indicate that only three variables are level stationary, while the rest four variables are first difference stationary. Since our dataset contains both $\mathrm{I}(0)$ and $\mathrm{I}(1)$ variables, we opt to apply pooled mean group (PMG) estimator, which is robust to this type of panel dataset.

\subsection{Empirical modelling}

Generally, the economic theory of production provides the analytical framework for most empirical research on productivity (Jorgenson and Griliches 1967; Nishimizu and Page 1982). Theory of production postulates a well-defined relationship between a vector of maximum producible outputs and a vector of inputs. If the production function is corrected for measurement error, the growth in TFP is largely explained by growth in inputs in the production process (Jorgenson and Griliches 1967). This study uses a time series analytical framework by incorporating $\mathrm{R} \& \mathrm{D}$, rainfall, variations in temperature, agricultural extension services and literacy rate in order to estimate the long-run relationship between these variables and agricultural TFP in Bangladesh.

Autoregressive distributive lag (ARDL) model has been in use for decades. More recently, ARDL has been shown to provide a very useful means for testing the presence of long-run relationships between economic variables in time series data. Such models can be used to test for co-integration and estimate long-run and short-run dynamics, even when variables may include a mixture of stationary and non-stationary time-series (Ghosh, 2009; Kim and Baek, 2013). In addition, the ARDL representation ameliorates some serious problems that entail in empirical studies, such as endogeneity and invalid hypothesis testing, surrounding conventional cointegration tests (Ang, 2009; Halicioglu, 2009). However, ARDL is applicable in a single cross-section unit. However, in a panel setting, there are multiple cross-section units with their individual effects. In such a setting, ARDL regression estimation becomes biased due to a correlation between mean-differenced regressors and the error term. To address this problem Arellano-Bond (1991) proposed dynamic panel data Generalised Methods of Moment 
(GMM) estimator; however, with a large dataset, the assumption under dynamic GMM are often not satisfied. To circumvent these issues, Pesaran et al (1999) extend the single crosssection ARDL model to panel setting and propose Pooled Mean Group (PMG) estimator (also known as panel ARDL). PMG estimator provides plenty of advantages for research with empirical data.

With traditional econometric methods, short-run relationships are modelled with stationary variables, such as ordinary panel regression or panel vector autoregression (PVAR) models and long-run relationships are modelled with non-stationary variables, such as panel cointegration, panel dynamic OLS or panel fully modified OLS. Very often researchers are interested to model the relationship between variables which may not be integrated at the same level, in which case above approaches (PVAR or panel cointegration) are not suitable for data in hand. PMG estimator is free from such restriction. This estimator can be applied to stationary as well as non-stationary variables (Zare et al., 2014); accordingly, it is not required to pre-test the stationary property of data. Another advantage of PMG estimator is that it provides estimates of coefficients both for long-run and short-run relationship.

Let in a panel setting, the long-run relationship between variable $y_{\mathrm{t}}$ and $\mathrm{x}_{\mathrm{t}}$ is modelled as follows:

$y_{i t}=\mu_{i}+\boldsymbol{\theta} \boldsymbol{x}_{i t}+\varepsilon_{i t}$

where, $\mu_{\mathrm{i}}$ is cross-section specific fixed effect, $i$ represents the number of cross-section units, and $t$ represents time. Pesaran et al. (1999) proposed to nest Equation (1) in a general ARDL framework as follows:

$y_{i t}=\mu_{i}+\sum_{j=1}^{p} \lambda_{i j} y_{i, t-j}+\sum_{j=0}^{q} \boldsymbol{\delta}_{i j}^{\prime} \boldsymbol{X}_{i, t-j}+\epsilon_{i t}$

where, $\mathbf{X}_{\mathrm{it}}$ is a $(k \times 1)$ vector of explanatory variables; $\lambda_{\mathrm{ij}}$ are coefficients of lagged dependent variables and $\delta_{\mathrm{ij}}$ is a $(k \times 1)$ vector of coefficients. Pesaran et al. (1999) show that the equation (2) can be reparametrized as an error-correction form as follows:

$\Delta y_{i t}=\mu_{i}+\emptyset_{i}\left(y_{i, t-1}-\boldsymbol{\theta}_{i}^{\prime} \boldsymbol{X}_{i t}\right)+\sum_{j=1}^{p-1} \lambda_{i j}^{*} \Delta y_{i, t-1}+\sum_{j=0}^{q-1} \delta_{i j}^{*} \Delta \boldsymbol{X}_{i, t-1}+\epsilon_{i t}$

where, $\emptyset_{i}=-\left(1-\sum_{j=1}^{p} \lambda_{i j}\right) ; \quad \theta_{i}=\sum_{j=0}^{q} \frac{\delta_{i j}}{\left(1-\sum_{k} \lambda_{i k}\right)} ; \lambda_{i j}^{*}=-\sum_{m=j+1}^{p} \lambda_{i m}, j=1,2, \ldots, p-1$; and $\delta_{i j}^{*}=-\sum_{m=j+1}^{q} \delta_{i m}, j=1,2, \ldots, q-1$.

The parameter vector $\boldsymbol{\theta}_{\boldsymbol{i}}^{\prime}$ contains the long-run or equilibrium relationship between 
dependent and independent variables. The parameter $\emptyset_{i}$ is the error correction term. It measures the speed of adjustment of $y_{i t}$ towards its long-run equilibrium value following a change in $\boldsymbol{X}_{\mathrm{it}}$. Therefore, a significantly negative $\emptyset_{i}$ value can be taken as evidence of cointegration between $y_{\mathrm{it}}$ and $\boldsymbol{X}_{\mathrm{it}}$. In our present case the dependent variable of yit is tfp and the vector $\underline{X}_{\mathrm{it}}$ contains the following variables (i) literacy (literacy); (ii) log of 30 years moving average rainfall (lrain30yma); (iii) log of 30 years moving average temperature (ltmp30yma); (iv) log of growing degrees month (lgdm); (v) log of R\&D expenditure (lrnd); and (vi) log of extension service (lext).

Table 2: Estimation results of Pooled Mean Group (PMG) and Mean Group (MG) models

\begin{tabular}{|c|c|c|}
\hline & PMG estimation & MG estimation \\
\hline \multicolumn{3}{|c|}{ Long-run coefficients } \\
\hline \multirow[t]{2}{*}{ lrndperfirm } & $0.0650 * * *$ & 0.0358 \\
\hline & $(0.0131)$ & $(0.0244)$ \\
\hline \multirow[t]{2}{*}{$\lg d m$} & 0.1152 & 0.4109 \\
\hline & $(0.5070)$ & $(0.4649)$ \\
\hline \multirow[t]{2}{*}{ lexperfirm } & $-0.1137 * * *$ & $-0.1005^{* * *}$ \\
\hline & $(0.0156)$ & $(0.016)$ \\
\hline \multirow[t]{2}{*}{ lrain30yma } & $-0.4471 * *$ & 0.7723 \\
\hline & $(0.1908)$ & $(0.5077)$ \\
\hline \multirow[t]{2}{*}{ ltmp30yma } & $-4.4739 * * *$ & -6.6316 \\
\hline & $(1.5110)$ & $(4.5251)$ \\
\hline \multirow[t]{2}{*}{ literacy } & $0.0104 * * *$ & $0.0092 * * *$ \\
\hline & $(0.0010)$ & $(0.0013)$ \\
\hline \multicolumn{3}{|c|}{ Short-run coefficients } \\
\hline \multirow[t]{2}{*}{ Error-correction } & $-0.5093 * * *$ & $-0.7011 * * *$ \\
\hline & $(0.0522)$ & $(0.0407)$ \\
\hline \multirow{2}{*}{ Alrndperfirm } & 0.0069 & -0.0151 \\
\hline & $(0.0119)$ & $(0.0266)$ \\
\hline \multirow{2}{*}{$\Delta l g d m$} & 0.0766 & -0.1204 \\
\hline & $(0.1557)$ & $(0.2350)$ \\
\hline \multirow{2}{*}{ Dlexperfirm } & 0.0084 & $0.0219^{*}$ \\
\hline & $(0.0089)$ & $(0.0115)$ \\
\hline \multirow{2}{*}{$\Delta$ lrain30yma } & 0.3731 & 0.4016 \\
\hline & $(0.4283)$ & $(0.5386)$ \\
\hline \multirow{2}{*}{ Altmp30yma } & $18.5599 * * *$ & $14.2937 *$ \\
\hline & $(5.6148)$ & $(7.4769)$ \\
\hline \multirow{2}{*}{$\Delta$ literacy } & 0.0012 & -0.0029 \\
\hline & $(0.0045)$ & $(0.0057)$ \\
\hline \multirow[t]{2}{*}{ Constant } & $3.9062 * * *$ & $5.4242 * * *$ \\
\hline & $(0.4000)$ & $(4.5267)$ \\
\hline
\end{tabular}

Three approaches are available to estimate the model specified in Equation (3). At one 
extreme fixed-effect (FE) approach can be applied, in which case intercept terms are allowed to vary across cross-section units, with slope coefficient being constant. However, in the case where the slopes of individual cross-section units are not identical, the FE estimators are inconsistent. On the other extreme, the model can be estimated with a mean group (MG) estimator proposed by Pesaran and Smith (1995), which allows intercept and slopes to vary across cross-section units. Pesaran et al (1999) propose an estimator that lies in between the above two extreme estimators. This intermediate estimator allows intercept and short-run coefficients (including error-correction term) to vary across cross-section units; however, restricts the long-run coefficients to be identical across all cross-section units. If the restriction of long-run coefficients homogeneity holds valid, PMG (Pooled mean group) approach yields more efficient estimator than MG. Pesaran et al (1999) propose a Hausman-type test with the null hypothesis of long-run coefficient homogeneity. If the test fails to reject the null hypothesis, the PMG estimator is preferred to MG estimator.

\section{Empirical results:}

\subsection{Pooled Mean Group estimation results}

Table 2 reports the estimation results of Equation (3) with both PMG and MG estimators. Errorcorrection coefficient indicates that MG estimator has faster adjustment toward the long-run value, which also has a smaller standard error. Long-run coefficients of PMG estimator generally have smaller standard errors than those in MG estimator. This efficiency is gained by imposing the restriction of long-run homogeneity. However, in order to make sure that this long-run homogeneity restriction is valid and we should proceed with PMG results, a Hausman-type test is conducted. The test statistic follows a $\chi^{2}(k)$ distribution, where $k$ is the number of independent variables. The test yields a test statistic of $\chi 2(6)=9.38$ with a probability value of 0.1534 . We, therefore, fail to reject the null hypothesis that PMG is preferred to MG estimator. Accordingly, we focus on PMG estimation results in the rest of the analysis.

Before explaining long-run and short-run coefficients, we need to check if the variables are cointegrated. The error correction term is highly significant and has expected negative signs. This indicates that total factor productivity and its determinants are cointegrated. The coefficient of error correction term implies that in the short run approximately $51 \%$ deviation from the long-run equilibrium relationship is adjusted each year, that is, the long-run relationship is restored in less than two years. Due care needs to be taken in explaining the coefficients. Dependent variable ( $t f p$ ) is an index, while except literacy, all five independent 
variables are in logarithmic form. Therefore, in explaining the coefficients of log variable, we must multiply the estimated coefficient by $0.01 .^{2}$ Except for the log of growing degrees month $(\lg d m)$, all coefficients are highly significant. In particular, the focus of this study, R\&D significantly affect TFP in the long run. For every $1 \%$ increase in the R\&D expenditure increases TFP index by 0.00065 in the long run. Similarly, a $1 \%$ increase in literacy rate increases the TFP index by 0.0104 in the long run. These two findings together have important policy implications. In order to increase productivity in the agriculture sector, the government of Bangladesh should allocate more funds in education, research and development sector.

For example, both Rahman and Salim, (2013) and Coelli et al. (2002) emphasized the need to invest in R\&D to enhance agricultural TFP in Bangladesh. Similarly, Asadullah and Rahman (2009) concluded that education significantly increases rice productivity and potential output in Bangladesh. The significant negative impact of extension expenditure is quite puzzling. Coelli et al (2003) argued that the competition of funds between R\&D and extension services may be the reason for the negative effect of extension expenditure on agricultural TFP growth in Bangladesh, which we also concur with.

Table 3: Short-run coefficients for individual cross-section unit

\begin{tabular}{|c|c|c|c|c|c|c|c|c|}
\hline & $\mathrm{EC}$ & $\Delta$ lrnd & $\Delta \operatorname{lgdm}$ & $\Delta$ lextension & $\Delta$ lrain30yma & $\Delta$ ltmp30yma & $\Delta$ literacy & Constant \\
\hline \multirow[t]{2}{*}{ Bandarban } & $-0.0797 * * *$ & 0.0688 *** & $0.9166^{* *}$ & $-0.0284 * * *$ & 0.4645 & 3.9387 & $-0.0092^{* * * *}$ & $0.6025 * *$ \\
\hline & $(0.0025)$ & $(0.0023)$ & $(0.2835)$ & $(0.0019)$ & (3.5978) & $(470.72)$ & $(0.0002)$ & $(0.1831)$ \\
\hline \multirow[t]{2}{*}{ Barisal } & $-0.3597 * * *$ & $0.0230 * *$ & 0.6351 & $0.0304 * * *$ & -0.8981 & 84.2345 & $0.0054 * * *$ & 2.7100 \\
\hline & $(0.0090)$ & $(0.0040)$ & $(0.7637)$ & $(0.0038)$ & $(8.1440)$ & (1243.82) & $(0.0005)$ & $(1.3421)$ \\
\hline \multirow[t]{2}{*}{ Bogra } & $-0.9140 * * *$ & $0.0480 * * *$ & -0.3075 & $0.0409 * * *$ & -0.7588 & 7.1956 & $-0.0162 * * *$ & 6.9457 \\
\hline & (0.0174) & $(0.0016)$ & $(0.2839)$ & $(0.0013)$ & (2.1744) & (448.73) & $(0.0002)$ & $(6.3806)$ \\
\hline \multirow[t]{2}{*}{ Chittagong } & $-0.7012 * * *$ & $0.0626 * * *$ & 0.2658 & $0.0544 * * *$ & 0.8977 & 33.9106 & $-0.0241 * * *$ & 5.3193 \\
\hline & (0.0157) & $(0.0017)$ & $(0.3816)$ & $(0.0013)$ & $(2.6434)$ & $(766.72)$ & $(0.0001)$ & (4.0457) \\
\hline \multirow[t]{2}{*}{ Comilla } & $-0.5354 * * *$ & $-0.0266 * * *$ & $0.8726^{*}$ & $-0.0621 * * *$ & 2.9021 & 44.3448 & $-0.0124 * * *$ & 4.1458 \\
\hline & (0.0112) & $(0.0018)$ & $(0.3644)$ & $(0.0015)$ & (1.9287) & $(609.25)$ & (0.0004) & $(2.4630)$ \\
\hline \multirow[t]{2}{*}{ Dhaka } & $-0.0913 * * *$ & $0.0113 * * *$ & -0.1626 & $-0.0560 * * *$ & 0.3371 & 20.5441 & $-0.0048 * * *$ & $0.6887 * *$ \\
\hline & $(0.0021)$ & $(0.0012)$ & $(0.2252)$ & $(0.0012)$ & (1.4009) & (410.54) & $(0.0001)$ & (0.1689) \\
\hline \multirow[t]{2}{*}{ Dinajpur } & $-0.6096 * * *$ & $0.0367 * * *$ & $-0.8719 * *$ & -0.0011 & 1.3865 & -1.6726 & $-0.0045^{* * * *}$ & 4.6433 \\
\hline & $(0.0144)$ & $(0.0015)$ & $(0.2299)$ & $(0.0016)$ & $(2.1829)$ & (253.15) & $(0.0002)$ & $(2.9666)$ \\
\hline \multirow[t]{2}{*}{ Faridpur } & $-0.4665 * * *$ & $0.0248 * * *$ & 0.3646 & 0.0036 & 0.4224 & -1.3842 & $0.0196^{* * *}$ & 3.6080 \\
\hline & (0.0119) & $(0.0025)$ & $(0.5799)$ & $(0.0020)$ & $(4.3453)$ & (1321.77) & $(0.0004)$ & $(2.0637)$ \\
\hline \multirow[t]{2}{*}{ Jessore } & $-0.6345 * * *$ & $0.0147 * * *$ & $0.7663^{*}$ & $0.0292 * * *$ & 4.7530 & 31.3225 & $0.0506^{* * *}$ & 4.8336 \\
\hline & $(0.0126)$ & $(0.0015)$ & $(0.2993)$ & $(0.0014)$ & $(2.2897)$ & (422.79) & $(0.0002)$ & (3.0674) \\
\hline \multirow[t]{2}{*}{ Khulna } & $-0.4072 * * *$ & 0.0515 *** & 0.7668 & $-0.0126 * *$ & -1.3370 & 9.6227 & $-0.0184 * * * *$ & 3.0560 \\
\hline & (0.0098) & $(0.0022)$ & $(0.3757)$ & $(0.0024)$ & $(2.6401)$ & $(455.91)$ & (0.0004) & (1.6708) \\
\hline \multirow[t]{2}{*}{ Kushtia } & $-0.4173 * * *$ & $-0.0456 * * *$ & -0.2958 & $0.0624 * * *$ & -2.1371 & -14.5351 & $-0.0067 * * *$ & 3.2264 \\
\hline & $(0.0112)$ & $(0.0027)$ & $(0.5108)$ & $(0.0024)$ & (4.3314) & (1004.77) & $(0.0006)$ & (1.8615) \\
\hline \multirow[t]{2}{*}{ Mymensingh } & $-0.5547 * * *$ & $-0.0930 * * *$ & -0.2079 & $-0.0218 * * *$ & -0.0191 & -1.8300 & $0.0245^{* * *}$ & 4.3484 \\
\hline & $(0.0111)$ & $(0.0013)$ & $(0.1899)$ & $(0.0012)$ & (1.8387) & (349.52) & $(0.0002)$ & $(2.7752)$ \\
\hline \multirow[t]{2}{*}{ Noakhali } & $-0.5217 * * *$ & $0.0062 * *$ & $-1.0136^{* *}$ & $0.0058 * *$ & 2.2498 & 14.1100 & $0.0056 * * *$ & 4.0249 \\
\hline & (0.0119) & $(0.0015)$ & $(0.2466)$ & $(0.0013)$ & (3.3614) & (397.53) & $(0.0001)$ & $(2.5052)$ \\
\hline \multirow[t]{2}{*}{ Pabna } & $-0.5487 * * *$ & $-0.0228 * * *$ & 0.5878 & $0.0090 * *$ & 0.4739 & 17.9245 & $-0.0157 * * *$ & 4.2137 \\
\hline & (0.0137) & $(0.0017)$ & $(0.3812)$ & $(0.0016)$ & (1.6344) & (436.97) & $(0.0003)$ & $(2.6159)$ \\
\hline \multirow[t]{2}{*}{ Rajshahi } & $-0.8372 * * *$ & $0.0196^{* * *}$ & -0.5221 & $0.0556^{* * *}$ & 0.6263 & 36.2153 & $0.0101 * * *$ & 6.4437 \\
\hline & (0.0144) & (0.0013) & $(0.3008)$ & $(0.0013)$ & (1.6574) & (391.28) & $(0.0002)$ & $(5.6381)$ \\
\hline \multirow[t]{2}{*}{ Rangpur } & $-0.5132 * * *$ & $-0.0835 * * *$ & $-0.7621 * *$ & $0.0300 * * *$ & -1.3758 & 8.4111 & $0.00086 * * *$ & 4.0053 \\
\hline & $(0.0091)$ & (0.0011) & $(0.2040)$ & $(0.0009)$ & $(0.9644)$ & (241.84) & $(0.00015)$ & $(2.1436)$ \\
\hline \multirow[t]{2}{*}{ Sylhet } & $-0.4658 * * *$ & $-0.0079 * * *$ & 0.2693 & $0.0046^{* *}$ & -1.6451 & 23.1457 & $0.0158 * * *$ & 3.5883 \\
\hline & $(0.0111)$ & $(0.0013)$ & $(0.3062)$ & $(0.0012)$ & $(2.9369)$ & $(576.85)$ & $(0.0002)$ & $(2.0582)$ \\
\hline
\end{tabular}

\footnotetext{
${ }^{2}$ Please see Gujarati (2012, p.34-36) for an excellent discussion on the explanation of such coefficients.
} 
Two climate change variables, Irain30yma and ltmp30yma have significant negative impacts on the TFP index. For each per cent increase in rainfall and Celsius degree temperature TFP index fall by 0.0037 and 0.1855 respectively. These results are in line with previous findings (see, for example, Chalise et al. (2017) and Iqbal and Siddique (2015)) as well as the empirical trend in global climate change. Bangladesh is known to be prone to devastating flood each year caused by heavy rainfall during the rainy season, which causes heavy loss to agriculture. Moreover, the increasing temperature is a global phenomenon. Bangladesh is no exception to this. The impact of the other climate change variable $l g d m$ is not statistically significant from zero. In Bangladesh temperature crosses the upper and lower threshold in very few occasions, hence GDM does not seem to have any significant effect on TFP. Among shortrun panel coefficients, only the temperature is found to be significant. Other variables do not have any significant impact on TFP in the short run.

Short-run coefficients for individual cross-section units are reported in Table 3. The results show that Bandarban and Dhaka have the lowest adjustment speed as indicated by the error correction (EC) values of 0.0797 and 0.0913 respectively. In other words, these two districts take more than 12 and 11 years respectively to adjust short-run disequilibrium. These results are reasonable since Bandarban is a hilly district, not suitable for traditional agricultural production and Dhaka is mostly urban district, not specialised in agriculture. Error correction values for other districts are reasonably high. $R \& D$, extension service and literacy are most significant; however, in several districts the coefficients are negative. Since we use yearly data, the short-run coefficient values indicate how the changes in these variables affect TFP in oneyear time; however, none of these three variables can exert expected influence in one-year time. The appropriate approach to trace the dynamics of the short-run impact of these variables on TFP is to estimate a panel vector autoregression (PVAR) and examine the graphs of its impulse response functions (IRFs). The impulse response function shows the response or reaction of one variable to the innovation shock or impulse in another variable.

\subsection{Panel Vector Autoregression (PVAR) and Panel Impulse Response Functions (PIRFs)}

For PVAR ${ }^{3}$ estimation we need stationary variables, otherwise, the estimated PVAR will not be stable. However, unit root test results reported in Table 1 show that tfp and lgdm are stationary and lrnd is non-stationary in all test results, while other variables are stationary in at least one test results. Therefore, in our PVAR estimation, we include the log difference of lrnd

\footnotetext{
${ }^{3}$ Details of PVAR can be found in Holts-Eakin et al (1988)
} 
(lrndgr) and other variables at their level. Since climate variables (lgdm, lrain30yma, and ltmp30yma) are strictly exogenous ${ }^{4}$, these variables are included in the exogenous variable list of the PVAR. It is important to note that variable ordering plays an important role in PIRFs. Variables ordered first have contemporaneous as well as lagged effects on the variables ordered later, while the variables ordered later have only lagged effect on the variables ordered first (Love and Zicchino, 2006; Berdiev et al., 2015). That is variables that are ordered first are more exogenous, while variables that are ordered later are more endogenous. In our baseline PMG estimation, we consider $t f p$ as the dependent variable; therefore, we consider this variable as the most endogenous and order it last in our PVAR estimation. Other three variables (lrnd, lext, and literacy) are considered less endogenous and ordered first.

\section{Figure 2: Impulse response function (IRF) from Panel VAR}
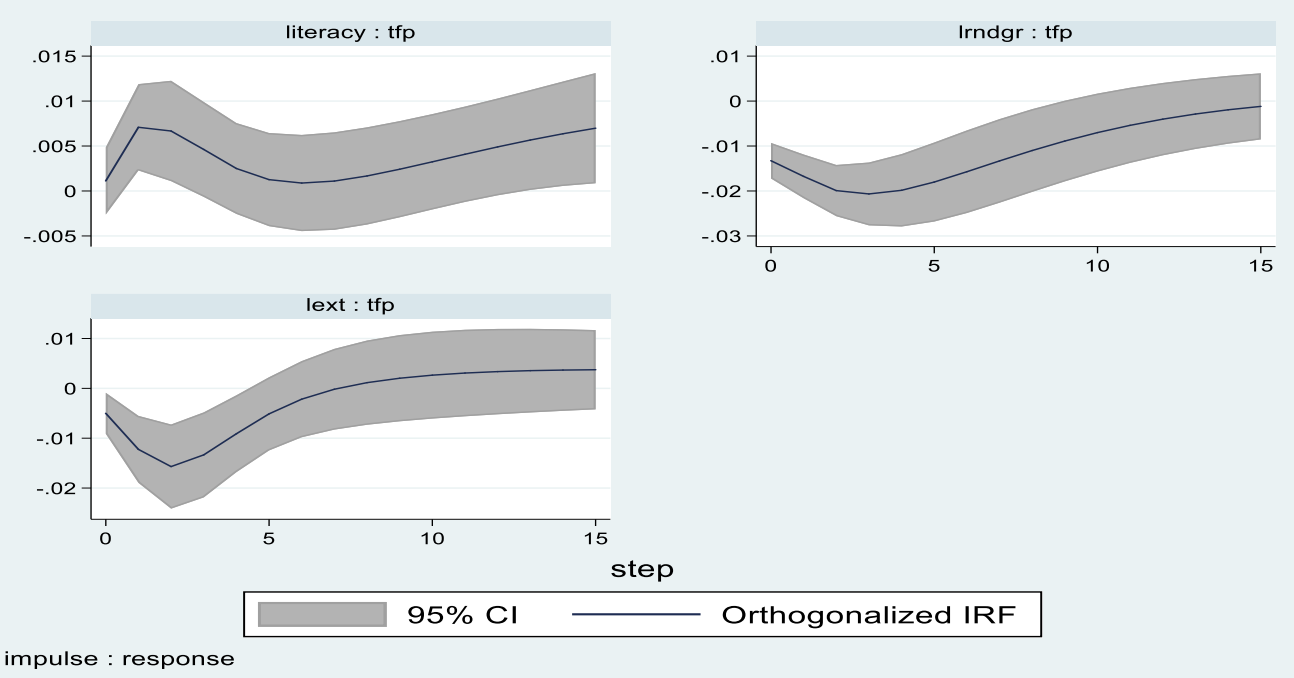

Note: In the figure above, the first variable is the impulse variable and the second variable is the response variable.

Our next consideration is selecting the optimum lag length for PVAR. We follow Andrews and Lu (2001) who propose consistent model and moment selection criteria (MMSC) for GMMbased panel data model. There are three MMSC statistic based on widely used maximumlikelihood criteria AIC, BIC and HQ, which are termed as MAIC, MBIC, and MQIC respectively. Table A2 in Appendix A reports these three statistics. Two (MBIC and MQIC), out of three criteria select lag 2 as optimum, while MAIC selects lag 3 as optimum. We take results given by the two selection criteria and estimate PVAR with 2 lags. Since our panel unit root tests do not give conclusive results on the stationarity of the variables under consideration, it is essential to make sure that the estimated PVAR system is stable. A stable VAR is invertible

\footnotetext{
${ }^{4}$ These variables are determined outside our PVAR, in fact they are determined outside this planet.
} 
and has an infinite order vector moving average representation and the impulse response function of a stable VAR has valid interpretation (Hamilton, 1994; Lutkepohl, 2005). Accordingly, after estimation, we examine the stability condition of the estimated PVAR. Figure A1 in Appendix A clearly shows that all the eigenvalues lie inside the unit circle, that is, the estimated PVAR satisfies stability condition. Now we generate response dynamics of tfp for one standard deviation shock to the residuals of each of lrndgr, lext and literacy equations in the estimated PVAR system. The resulting PIRFs are plotted in Figure 2. The PIRFs show that shock to lrndgr cause tfp to fall initially and then rises steadily and moves toward the positive region in the long run. Extension service also has a negative impact initially; however, it rises rapidly and become positive in approximately 7 years' time. The response of $t f p$ to literacy shock is positive and it trends toward the positive region in the long run. In short, although total factor productivity responds negatively in the short run to shock to extension service and $R \& D$ expenditure, the response dynamics move to the positive region in the long run.

\section{Conclusions and policy implications}

This study examines the impact of R\&D investment on agricultural TFP in Bangladesh based on a unique panel data of 17 regions covering the 61-year period (1948-2008). Other control variables include agricultural extension services, rainfall, temperature variations (growing degrees month), and literacy rate. We employ the panel counterpart of the ARDL model, known as pooled mean group (PMG) estimator to estimate the long-run relationship among the variables of interest. In addition, we also employ the panel vector autoregression (PVAR) model to trace responsiveness of total factor productivity from a shock to $R \& D$, extension services, and literacy rate. The empirical results indicate that there are long-run equilibrium relationships between agricultural TFP and $R \& D$, and other control variables. Any temporary deviation from this long-run relationship is corrected in less than two years' time as indicated by the error correction coefficient of 0.51 . In the long run, $R \& D$ has a positive and significant impact on TFP. The estimated positive effect of R\&D might contribute to the estimated technological progress, which grew at a rate of 0.74 per cent per annum (Rahman and Salim, 2013).

In the short-run R\&D is found to have an insignificant impact on TFP, which is in line with both empirical evidence and theoretical argument. Empirically Huffman and Evenson (2006) document that the impact of R\&D takes a longer time to work, which is not captured 
within one year. This is also consistent with the theoretical argument that R\&D investment takes time to be effective in increasing productivity. The contributions of climate variables (i.e., rainfall and temperature variations) are highly significant and negative in the long run. These findings are in line with the popular belief that climate change is a significant and negative determinant of agricultural productivity. The literacy rate is found to have a significant positive impact on TFP as expected. The panel impulse response from panel VAR is employed to trace out the impact of any shock to R\&D and other variables on TFP. Results from the panel impulse response functions show that TFP initially responds negatively to one unit shock to the error of R\&D equation in the panel VAR system, however, in the long run, it approaches towards the positive region. TFP exhibits a similar response to one unit shock to the error of extension services equation.

Some policy implications emerge from the above findings. The recent agricultural TFP growth may partly be attributable to increasing government investment R\&D in Bangladesh (see Nagy and Alam, 2002). Given the rising demand for food for the continuously growing population in Bangladesh, an increase in agricultural productivity is essential. Therefore, we recommend continued investment in agricultural $R \& D$ as an appropriate policy option for Bangladesh which was echoed by Rahman and Salim (2013) and the country should envisage raising the intensity ratio of $R \& D$ investment to agricultural GDP towards the recommended 1 per cent mark as recommended by Beintena and Stads (2003). The thrust of R\&D investment should be on developing crop varieties which are responsive to high rainfall and/or can withstand climate variabilities as noted by Rahman (2016). Coelli et al. (2002) also noted that little attention has been paid in $R \& D$ to develop varieties that are suitable for unfavourable regions in Bangladesh. Next, we suggest for investment in education targeting the farming community, along with the modernization of the agricultural/farming education system as Asadullah and Rahman (2009) demonstrated that the impact of education kicks in from the secondary level of education onward in improving productivity and efficiency in rice farming in Bangladesh. Other priorities include cropping system development in line with the adaptation to climate change as mentioned above. However, institutional strengthening, research priority setting, and building agricultural research capacity are no less important.

Acknowledgement: The authors are grateful to Drs. Farid U Khan from Rajshahi University, and S. A. K. Mamun from National University, Bangladesh for excellent research assistance 
in the earlier version of this paper. The authors are also grateful to the anonymous reviewer for providing useful comments and suggestions which materially improved the quality and presentation of this article. However, the usual disclaimer applies. 


\section{References}

Alam, M. A. (2018) The Effect of the 'Subsidy on Fertilizer' on Food Prices in Bangladesh and Policy Options, Journal of Economics and Sustainable Development, 9: 200-208.

Andersen, M. A., and Song, W., (2013). "The economic impact of public agricultural research and development in the United States". Agriculture Economics, 44, 287-293.

Andrews, D.W.K., Lu, B., 2001. Consistent model and moment selection procedure for GMM estimation with application to dynamic panel data models. Journal of Econometrics 101(1): 123-164.

Ang, J.B., 2009. CO2 emissions, research and technology transfer in China. Ecological Economics 68, 2658-2665.

Arellano, M., Bond, S., 1991. Some tests of specification for panel data: Monte Carlo evidence and an application to employment equations. Review of Economic Studies 58: 277-97.

Asadullah, M.N., Rahman, S. 2009. "Farm productivity and efficiency in rural Bangladesh: the role of education revisited". Applied Economics, 41(1): 17-33.

Baltagi, B.H., Griffin, and Xiong, W., (2000). "To pool or not to pool: homogeneous versus heterogeneous estimators applied to cigarette demand". Review of Economics and Statistics, 82, 117-126.

Berdiev, A.N., Pasquesi-Hill, C., Saunoris, J.W., 2015. Exploring the dynamics of the shadow economy across US states. Applied Economics 47(56), 6136 - 6147.

Breitung, J. (2000). "The local power of some unit root tests for panel data" in B. H. Baltagi (ed.), Advances in Econometrics. Non-stationary Panels, Panel Cointegration, and Dynamic Panels. Amsterdam: JAI Press 15: 161-78.

Chalise, S., Naranpanawa, A., Bandara, J. S. and Sarker, T. (2017). A general equilibrium assessment of climate change-induced loss of agricultural productivity in Nepal. Economic Modelling 62: 43 - 50.

Coelli, T., Rahman S., Thirtle, C. 2003. "A stochastic frontier approach to total factor productivity measurement in Bangladesh crop agriculture, 1961-1992”. Journal of International Development. Vol. 15(3): 321-333.

Deb, U (2016) Agricultural Transformation in Bangladesh: Extent, Drivers and Implications, Paper presented at the 15th National Conference of the Bangladesh Agricultural Economists Association (BAEA) on "Transformation of Agricultural Sector in Bangladesh: 21st Century" held on 22-23 January 2016 at the Bangladesh Agricultural Research Council (BARC), Dhaka, Bangladesh

Ghosh, S., 2009. Import demand of crude oil and economic growth: Evidence from India. Energy Policy 37, 699-702.

Gujarati, D. (2012). Econometrics By Example, Pulgrave Macmillan, UK.

Halicioglu, F., 2009. An econometric study of CO2 emissions, energy consumption, income and foreign trade in Turkey. Energy Policy 37, 1156-1164.

Hamilton, J.D. (1994). Time Series Analysis. Princeton: Princeton University Press.

Huffman, W. E., Everson, R.E. (2006). “Do formula or competitive grant funds have greater impacts on state on agricultural productivity". American Journal of Agriculture, 88(4), 
783-798.

Im, K. S., Pesaran, M. H. and Shin, Y. (2003). "Testing for Unit Roots in Heterogeneous Panels.

" Journal of Econometrics 115: 53-74.

International Food Policy Research Institute (IFPRI) (2008). Agricultural $R \& D$ capacity and investments in the Asia-Pacific region. Research Brief 11. Washington D C: International Food Policy Research Institute.

Iqbal, K. and Siddique, M.A.B. (2015). The impact of climate change on agricultural productivity: evidence from panel data of Bangladesh. Journal of Developing Area 49(6): $89-101$.

Jorgenson, D. W. and Griliches, Z. (1967), "The explanation of productivity change," The Review of Economic Studies, 34, 249-283.

Kangasniemi, M., Mas, M., and Robinson, C., (2012). The economic impact of migration: Productivity analysis for Spain and the UK. Journal of Productivity Analysis, 38, 333343.

Karim, Z. (1997). "Accelerated agricultural growth in Bangladesh". Seminar paper. Agricultural Research on Development in Bangladesh. Bangladesh Agricultural Research Council.

Kim, H.S., Baek, J., 2013. Assessing dynamics of crude oil import demand in Korea. Economic Modelling 35, 260-263.

Love, I., Zicchino, L., 2006. Financial development and dynamic investment behavior: evidence from panel VAR. The Quarterly review of Economics and Finance 46, 190 -210 .

Lutkepohl, H. (2005). New Introduction to Multiple Time Series Analysis. New York:

Springer

Maddala, G.M. (2001). Introduction to Econometrics: Third edition. England:John Wiley \& Sons Ltd.

Mohammadi, H. and Parvaresh, S. (2014). "Energy consumption and output: evidence from a panel of 14 oil-exporting countries". Energy Economics, 41, 41-46.

Mondol, M. H., (2010). 'Crop agriculture of Bangladesh: Challenges and opportunities'. Bangladesh Journal of Agricultural Research, 35 (2), 235-245.

Mullen, J. D. (2010). "Trends in investment in agricultural R\&D in Australia and its potential contribution to productivity." Australasian Agribusiness Review, University of Melbourne, Melbourne School of Land and Environment Vol.18.

Nagy, J.G. and Alam, M.F. 2002. The Impact of Agricultural Research in Bangladesh: Estimating Returns to Agricultural Research, International Conference on Impact of Agricultural Research and Development February 4-7, San Jose, Costa Rica.

Nishimizu, M., and Page, J. M., (1982) 'Total factor productivity growth: technological 
progress and technological efficiency change: dimension of productivity change in Yugoslavia 1965-78' The Economic Journal, 92 (368),920-936.

O’Donnell, C. J. (2010). "Measuring and decomposing agricultural productivity and profitability change." Australian Journal of Agricultural and Resource Economics 54: 527-560.

Pardey, P.G., Alston, J. M.< and Piggot, R. R. (2006). Agricultural $R \& D$ in the developing world: too little, too late?, International Food Policy Research Institute, Washington, D C.

Persyn, D. and Westerlund, J. (2008) "Error-correction-based cointegration tests for panel data ". The Stata Journal 8, 232-241.

Pesaran, M. H. (2007). "A simple panel unit root test in the presence of cross section dependence." Journal of Applied Econometrics 27: 265-312

Pesaran, M. H., and Smith, R. P. (1995). "Estimating long-run relationships from dynamic heterogeneous panels." Journal of Econometrics 68: 79-113.

Pesaran, M. H., Y. Shin, and Smith, R. P. (1997). "Estimating long-run relationships in dynamic heterogeneous panels." DAE Working Papers Amalgamated Series 9721.

Pesaran, M. H., Y. Shin, and Smith, R. P. (1999). "Pooled mean group estimation of dynamic heterogeneous panels." Journal of the American Statistical Association 94: 621-634.

Rahija, M., Hossain, S.M. M., Rahman, M.M. and Stads, G.-J. (2011). " Bangladesh: recent developments in public agricultural research". Bangladesh Agricultural Research Council Country and Agricultural Science and Technology Indicators Note. IFRI, USA.

Rahman, S. 2016. "Impacts of climate change, agroecology and socio-economic factors on agricultural land use diversity in Bangladesh (1948-2008)". Land Use Policy, Vol. 50(1): $160-178$.

Rahman, S., and Salim, R. (2013). "Six Decades of Total Factor Productivity Change and Sources of Growth in Bangladesh Agriculture (1948-2008)." Journal of Agricultural Economics 64(2): 275-294.

Salim, R., and Islam, N. (2010). "Exploring the impact of R\&D and climate change on agricultural productivity growth: the case of Western Australia2. Australian Journal of Agricultural and Resource Economics, 54: 561-582.

Thirtle, C., Piesse, J. and Schimmelpfennig, D. (2008). Modelling the Length and Shape of th R\&D Lag: An Application to UK Agricultural Productivity, Agricultural Economics, 39, 73-85.

Zare, R., Azali, M., Habibullah, M.S. and Azman-Saini, W.N.W. (2014). Monetary policy 
effectiveness and stock market cycles in ASEAN-5., Applied Economics, 46, 2362 2374. 
Appendix A

Table A2: Lag length selection criteria for panel VAR

\begin{tabular}{crrr}
\hline Lag & MBIC & MAIC & MQIC \\
\hline 1 & -75.193 & 233.427 & 115.644 \\
2 & -217.453 & 14.012 & -74.325 \\
3 & -167.338 & -13.028 & -71.920 \\
4 & -78.238 & -1.083 & -30.528 \\
\hline
\end{tabular}

Figure A1: PVAR stability condition

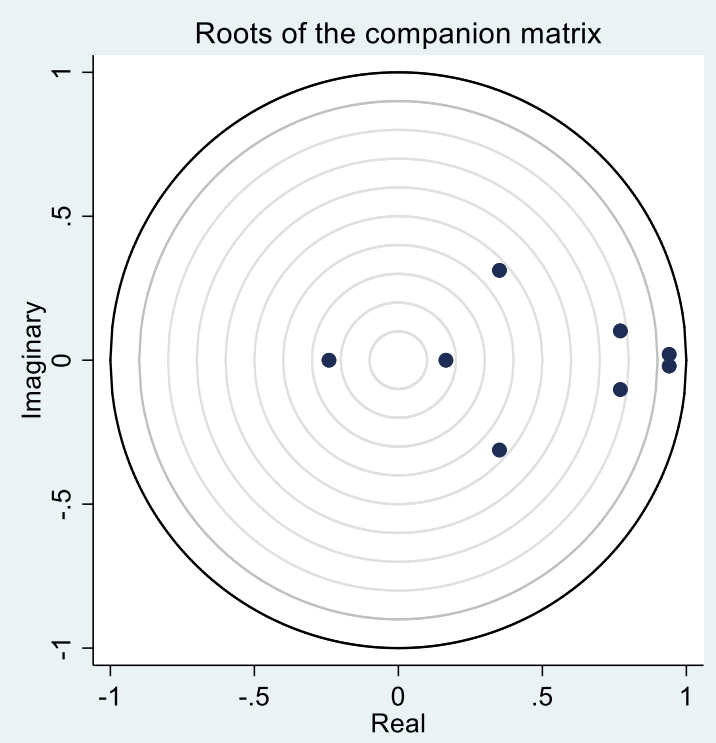

